\title{
Measurement Instruments
}

At right, National Bureau of Standards (NBS) engineer Steve Treado is using an instrument called the Willey Alpha Meter to measure the reflectivity of a mirrored substance commonly used in manufacture of windows. Below left, Treado is using the meter with a projector attachment to check the reflectivity of a wall in a test unit at the NBS Center for Building Technology. Treado's work involves research toward optimizing window energy performance and design of window controls and lighting controls. He develops a model to measure interior daylight, then tests to see how it
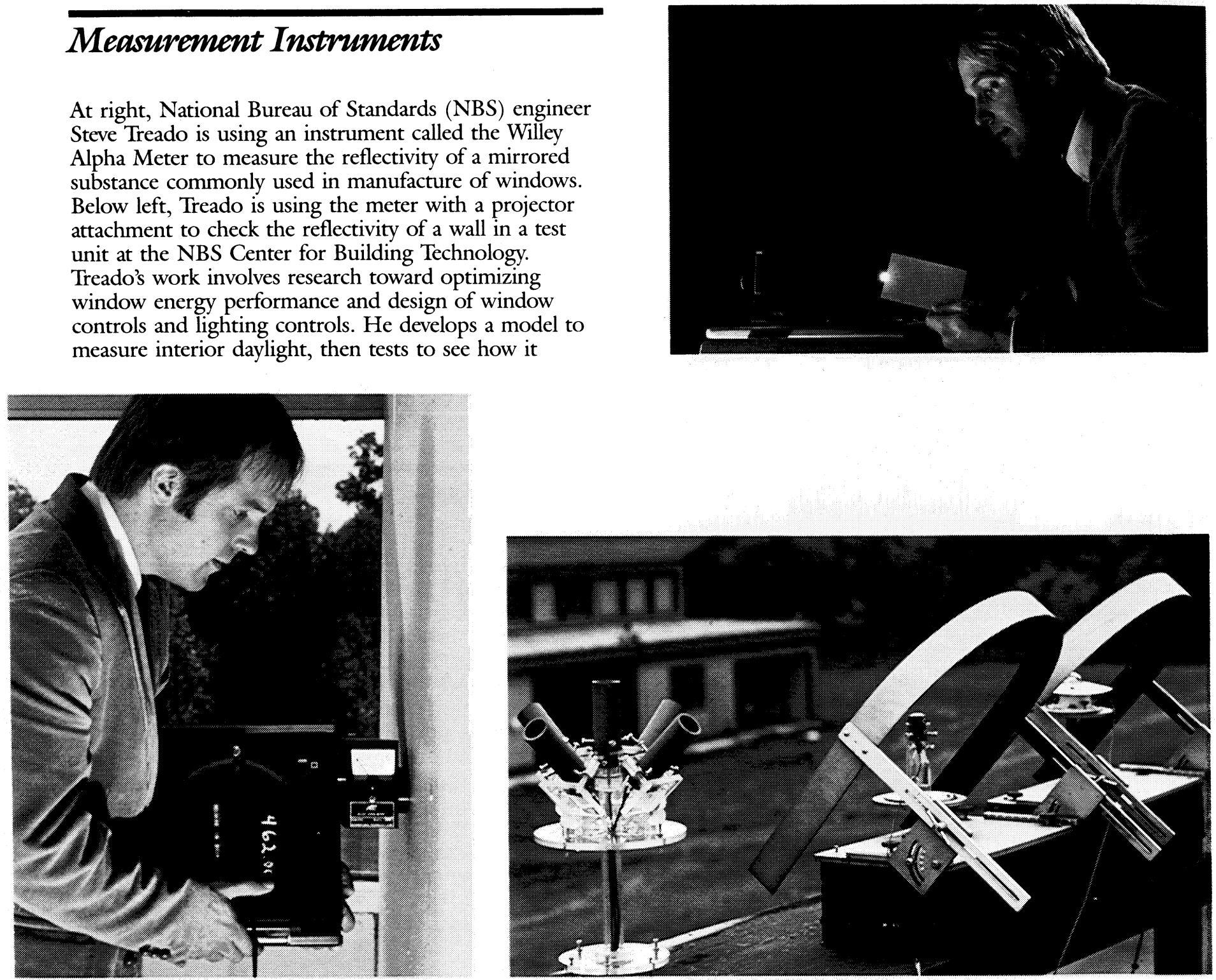

compares with actual daylight. He employs several types of instruments to measure daylight (above right) and instruments like the Alpha Meter to measure the optical properties of various window and interior materials.

The Willey Alpha Meter is one of a line of instruments - manufactured by International Technology Corporation (INTEC), Satellite Beach, Florida-for determining the optical properties of materials used in solar energy applications. Some of the INTEC instruments are based on NASA technology, including the Willey Alpha Meter and the McDonald Emissometer. The latter instrument was the first of the INTEC line, introduced in 1976; it is a commercial version of a system developed by Lewis Research Center to test efficiency-increasing coatings on solar panels. The emissometer tests a coating sample to determine its emissivity, the degree to which it emits radiant energy. Such measurements are important because the best coatings are those that absorb maximum solar heat with minimal emittance of infrared radiation, which occurs when the solar collector plate gets hot. Too much coating causes energy loss by emittance, too little reduces the collector's ability to absorb heat.
There was equipment available for testing emittance, but it was complex and expensive. To provide manufacturers of solar equipment an accurate but lower cost means of testing coatings, Lewis Research Center developed the McDonald Emissometer in conjunction with Willey Corporation, Melbourne, Florida and the University of Rochester. The instrument is placed above a pre-heated sample and a heat sensor determines the degree of emittance, which is displayed on the meter.

In 1979, INTEC expanded its line of commercial instruments with the Willey Alpha Meter to include measurements of reflectance-the amount of energy reflected by a surface-as well as emittance. The following year INTEC introduced the Ambient Emissometer, which directly heats the coating sample and produces emittance measurements similar to those of the McDonald Emissometer. INTEC's emissometers and reflectometers can be combined with a digital display unit also produced by the company. The company's instruments are in service in more than $\mathbf{4 0}$ countries; customers, in addition to manufacturers of solar equipment, include government, university and private research laboratories. 